\title{
Remote Sensing and Depth Distribution of Ocean Chlorophyll
}

\author{
Raymond C. Smith \\ Visibility Laboratory, Scripps Institution of Oceanography, University of California, San Diego, La Jolla, California 92093, USA.
}

ABSTRACT: This note considers how chlorophyll, as estimated from Coastal Zone Color Scanner (Nimbus 7 satellite) data, is related to the chlorophyll concentration in the oceanic water column. In spite of some limitations, the remotely sensed chlorophyll concentration can be used as an index of the mean water column chlorophyll. Chlorophyll imagery provides synoptic measurements, impractical to obtain from ships alone, and hence may be of considerable importance in phytoplankton ecology.

It has been demonstrated that data from the Coastal Zone Color Scanner (CZCS) on the Nimbus 7 satellite can be processed to provide quantitative chlorophyll maps of an oceanographic region within an accuracy of $0.5 \log C$ (Morel and Prieur, 1977; Gordon et al., 1980; Hovis et al., 1980; Smith and Baker, submitted, 1981). This note discusses the issue of how chlorophyll, as estimated from CZCS imagery, is related to the water column chlorophyll concentration.

The problem is best explored in terms of optical attenuation lengths as distinct from geometrical depths. Gordon and McCluney (1975) defined, $Z_{90}$, as the depth of penetration of light above which $90 \%$ of the diffusely reflected irradiance (excluding specular reflectance) originates. They showed that for a homogeneous ocean

$$
Z_{90} \approx K^{-1}
$$

where $K=$ diffuse attenuation coefficient for downwelling irradiance. More recently, it has been shown (Gordon and Clark, 1980), that for remote sensing purposes, the concentration of the constituent under consideration should be weighted by a factor

$$
g(Z)=\exp \left\{-2 \int_{0}^{Z} K(Z) \cdot d Z\right\}
$$

Frequently, as a first-order approximation, $K(Z)$ is considered approximately constant with depth so that,

$$
g(Z)=\exp \{-2 K \cdot Z\}
$$

Heuristically, this weighting factor can be viewed as being derived from the irradiance arriving at the surface having been attenuated by $\exp [-K \cdot Z]$ from the surface to the depth $Z$ and by the same factor on the return to the surface. Gordon and Clark (1980) conclude that the remotely sensed concentration of chlorophyll is given by

$$
C_{\text {SAT }}=\frac{\int_{0}^{Z_{40}} C(Z) \cdot g(Z) \cdot d Z}{\int_{0}^{Z_{40}} g(Z) \cdot d Z}
$$

where $C(Z)$ is the concentration of chlorophyll as a function of depth.

When shipboard chlorophyll has been determined at only a few discrete depths in the water column, then $C_{\mathrm{SAT}}$ may be approximated by the mean chlorophyll concentration to a depth of one attenuation length, $C_{K}$ (Smith and Baker, 1978a). The mean chlorophyll to the euphotic depth, $C_{T}$, is obtained from an integral of $C(Z)$ over 4.6 attenuation lengths (i.e. the $1 \%$ level). If, as is generally the case, $C(Z)$ is not too complex then $C_{S A T}$, $C_{K}$ and $C_{T}$ are highly correlated, as has been previously shown using data from 140 stations (Smith and Baker, 1978a). Thus $C_{\text {SAT }}$ can be used as an index of the mean chlorophyll concentration in the water column.

In order to illustrate this for a variety of water types, Fig. 1 and Table 1 show 3 chlorophyll profiles (Cullen and Eppley, 1981) ranging from productive coastal water to oligotrophic waters. It is useful to renormalize these profiles as shown in Fig. 2 where chlorophyll has been plotted as a function of attenuation lengths of photosynthetic available radiant energy (PAR). When plotted in this manner, a given percentage PAR level (the $1 \%$ euphotic depth for example) and/or the 


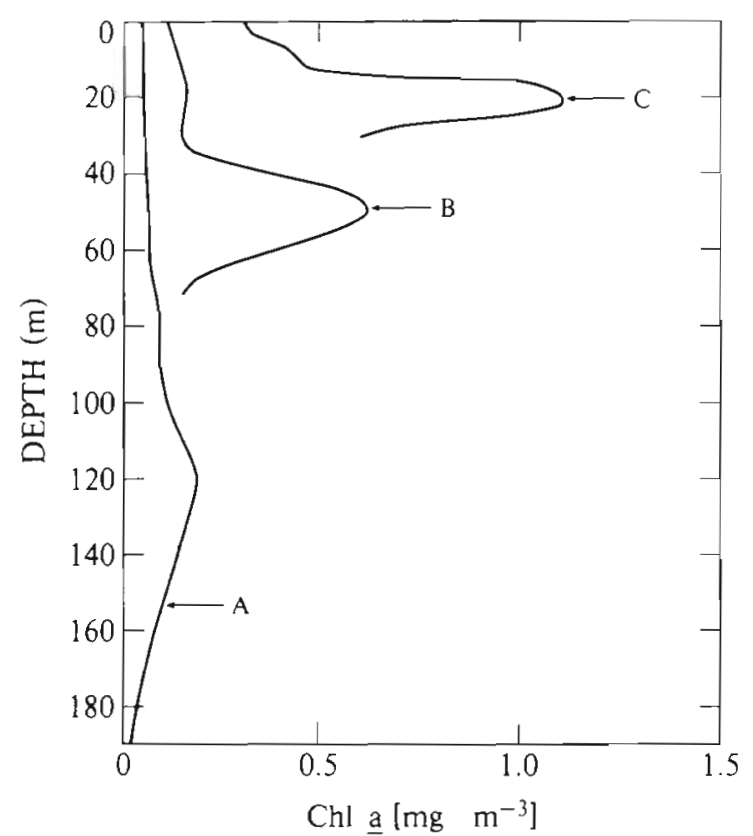

Fig. 1 Typical chlorophyll profiles plotted as function of geometrical depth (Cullen and Eppley, 1980): (A) North Pacific Central Gyre, near $28^{\circ} \mathrm{N}, 155^{\circ} \mathrm{W}$ (from Beers et al., 1975); (B) SCBS 15, Sta 205; (C) SCBS 7, Sta. 102

remote sensing penetration depth are directly comparable for waters with very different chlorophyll concentrations. Thus, $C_{\mathrm{SAT}}$ for these very different profiles would be proportional to the integral of the weighting function, $g(Z)$, times the profiles as shown in Fig. 2 and as given by Eq. (4). Fig. 2 illustrates that $C_{\mathrm{SAT}}$ is determined by a weighting of the top 20 to $30 \%$ of the euphotic zone, regardless of whether oligotrophic or highly productive conditions exist.

Several observations with repsect to Table 1 can be made. First, as one moves from oligotrophic to eutrophic waters the euphotic depth and the PAR penetration depth change together proportionally. Second, the

Table 1 Observations on 3 typical vertical profiles (after Cullen and Eppley, 1981): (A) North Pacific Central Gyre (Beers et. al., 1975) and Food Chain Research Group (Eppley, unpubl.); (B) Offshore Southern California Bight, SCBS 15 , Sta. 205; (C) Nearshore Southern California Bight, SCBS 7. Sta. 102

\begin{tabular}{|c|c|c|c|}
\hline & $A$ & B & $\mathrm{C}$ \\
\hline $\begin{array}{l}\text { Euphotic depth }(\mathrm{m}) \\
\text { PAR penetration depth }\end{array}$ & 105 & 66 & 33 \\
\hline$K_{P A R}^{-1}(m)$ & 22.8 & 1.4 .3 & 7.2 \\
\hline Integrated $\mathrm{Chl}\left(\mathrm{mg} \mathrm{m}^{-2}\right)$ & 18.5 & 19.8 & 20.2 \\
\hline $\begin{array}{l}\text { Mean Chl a, } C_{T}\left(\mathrm{mg} \mathrm{m}^{-3}\right) \\
\text { Satellite estimated } C h l\end{array}$ & 0.09 & 0.38 & 0.67 \\
\hline $\begin{array}{l}C_{\text {SAT }}\left(\mathrm{mg} \mathrm{m}^{-3}\right) \\
\text { Integrated primary production }\end{array}$ & 0.045 & 0.13 & 0.36 \\
\hline$P_{\mathrm{I}}\left(\mathrm{gm} \mathrm{m}^{-2} \mathrm{~d}^{-1}\right)$ & 0.054 & 0.162 & 0.516 \\
\hline
\end{tabular}

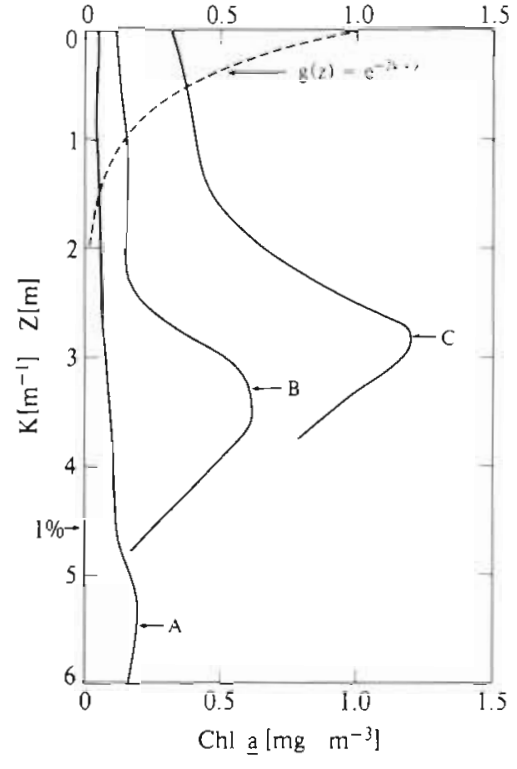

Fig. 2. Same profiles as in Fig. 2 plotted as function of attenuation lengths of PAR $\left(K_{\mathrm{PAR}} \cdot Z\right)$. The remote sensing weighting function, $g(Z)$, is shown as dashed curve. Depth of euphotic zone, taken as $1 \%$ PAR level, is indicated by an arrow on vertical scale

mean chlorophyll concentrations in the water column (to the $1 \%$ level), $C_{T}$, varies in a manner similar to $C_{\text {SAT }}$. Third, both $C_{\text {SAT }}$ and $C_{T}$ are correlated with the integrated primary production in the water column.

The wavelength dependence of $K$ is also important when considering the penetration depth. For calculations involving primary productivity it is generally most useful to consider a broadband width $K$ as the attenuation coefficient for PAR, defined so that

$$
\operatorname{PAR}(Z)=\operatorname{PAR}\left(\mathrm{O}^{-}\right) \exp \left(-K_{\mathrm{PAR}} \cdot Z\right)
$$

where $K_{P A R}$ is the diffuse attenuation coefficient for PAR ( 350 to $700 \mathrm{~nm}$ ). However, $K$ is also a function of each narrow band wavelength, in particular the four visible CZCS spectral bands $4443,520,550$, and $670 \mathrm{~nm}$ ). The CZCS spectral bands are relatively narrow $(\Delta \lambda=20 \mathrm{~nm}$ FWHM) so the depth of penetration will vary with each band. Our bio-optical model (Smith and Baker, 1978b; Baker and Smith, submitted, 1981), which gives the relationship between $K(\lambda)$ and $C$, can be used to show how the penetration depth varies with chlorophyll concentration in each CZCS spectral band.

In Fig. 3 the penetration depth, $Z_{90}$, has been calculated for four CZCS bands and for $K_{\mathrm{PAR}}$ as a function of chlorophyll concentration. This figure illustrates several points related to the remote sensing of chlorophyll. First, the penetration depth for all spectral bands becomes smaller as the chlorophyll concentration increases. Second, the penetration depth for PAR and the $520 \mathrm{~nm}$ band are nearly the same regardless of variations in $C$. This is consistent with the concept of a 
'hinge point' (Duntley et al., 1974), which is a wavelength band where changes in the upwelled spectral radiance are relatively insensitive to variations in chlorophyll. Third, $K_{(i 70)}^{-1}$ is only a few meters and relatively independent of $C$ because the attenuation in the red is dominated by the absorption of water Fourth, the penetration depth at 550 and $443 \mathrm{~nm}$ generally differ from $K_{\mathrm{PAR}}^{-1}$. Indeed, it is the difference in these bands that makes the remote sensing of chlorophyll possible.

There are a number of reasons why a remotely sensed estimate, $C_{\text {SAT, }}$ of the mean water column chlorophyll concentration, $C_{T}$, may be inexact: (1) normalization to single broadband penetration depth, $K_{\mathrm{PAR}}^{-1}$, while a good first approximation, neglects the wavelength dependency of the band width penetration depth used in the chlorophyll algorithm; (2) significant

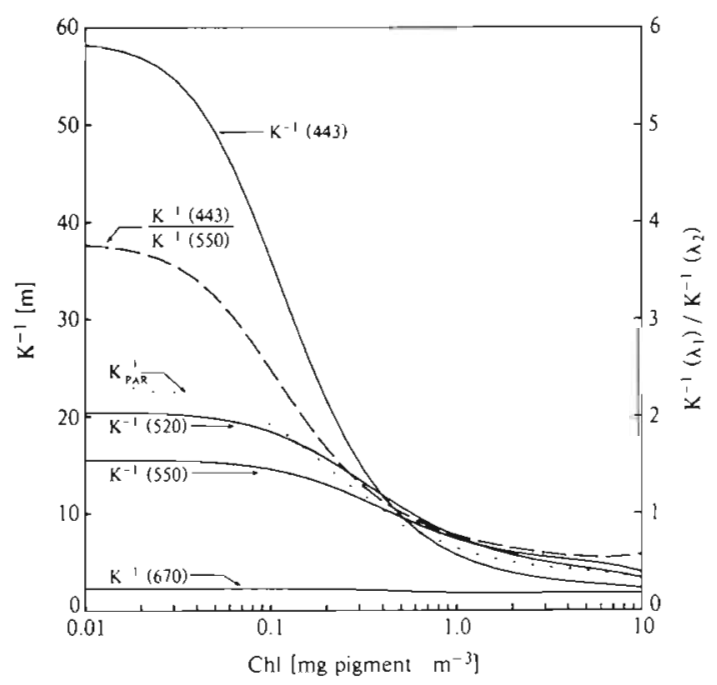

Fig. 3. Penetration depth, $Z_{y: 0}=K^{-1}(\mathrm{~m})$, versus chlorophyll concentration, $C\left(\mathrm{mg} \cdot \mathrm{m}^{-3}\right.$ ) as derived from an optical classification model (Smith and Baker, 1978b; Baker and Smith. 1981). Penetration depth calculated for 4 CZCS spectral bands $K_{,-1}^{-1}$ and for total photosynthetically available radiant energy, $K_{\text {PAR }}^{-1}$. Scale on right ordinate gives ratio of penetration depth in blue band to that in the green, $K_{44.3}^{-1} / K^{-1}, 50$

changes in the chlorophyll profiles at depth greater than a few attenuation lengths, without a proportional change in the top region of the profile, will go unnoticed by the satellite sensor; (3) shifts in the ratio of chlorophyll-like pigments (e.g. chlorophyll a and phaeophytin a) with depth do not change the optical signal.
In spite of these limitations, the examples illustrate that $C_{\text {SAT }}$ can be used as an index of the mean water column chlorophyll. The accuracy of this index has been studied and shown to be within less than $0.5 \mathrm{log}$ $C$ (Gordon et al., 1980; Smith and Baker, submitted, 1981). Since chlorophyll imagery can provide synoptic measurements impractical to obtain from ships alone, the CZCS data can be of considerable value in studies of phytoplankton ecology especially in complex coastal regions.

Acknowledgements. This work was completed with the support of NASA Grant No. NSG 1641 K. S. Baker and R. W Eppley provided valuable discussions and advice

\section{LITERATURE CITED}

Baker, K. S., Smith, R. C. (1981). Bio-optical classification and model of natural waters II. (submitted)

Beers, J. R., Reid, F. M. H., Stewart, G. L. (1975). Microplankton of the North-Pacific Central gyre. Population structures and abundance, June 1973. Int. Revule ges. Hydrobiol. 60: 607-638

Cullen, J. J., Eppley, R. W (1981). Chlorophyll maxımum layers of the Southern California Bight and possible mechanisms of their formation and mantenance. Ocoanol Acta 4: 23-32

Duntley, S. Q., Austın, R. W. Wılson, W H., Edgerton, C. F., Moran, S. E. (1974). Ocean color analysis. Scripps Inst. Oceanogr Ref. $74-10$

Gordon, H. R. Clark, D. K. (1980). Remote Sensing optical propertıes of a stratified ocean. Appl. Opt. 19:3428-3430

Gordon, H. R., Clark, D. K. Mueller, J. L., Hovis, W. A. (1980). Phytoplankton pigments from the Nimbus-7 Coastal Zone Color Scanner: comparison with surface measurements. Science, N.Y 210: 63-66

Gordon, H. R., McGluney, W R. (1975). Estimation of the depth of sunlight penetration in the sea for remote sensing. Appl. Opt. 14:413-416

Hovis, W. A., Clark, D. K., Anderson, F., Austin, R. W., Wilson, W H., Bkaer, E. T., Ball, D., Gordon, H. R., Mueller, J. L., El-Sayed, S. Z., Sturm, B., Wrigley, R. C., Yentsch, C. S. (1980). Nimbus-7 Coaslal Zone Color Scanner Systems: description and initial imagery. Science, N. Y 210: 60-63

Morel, A., Prieur, L. (1977). Analysis of variations in ocean color. Limnol. Oceanogr. 22: 709-722

Smith, R. C., Baker, K. S. (1981). Oceanic Chlorophyll concentrations as determined using Coastal Zone Color Scanner imagery. Mar Biol. (submitted)

Smith, R. C., Baker, K. S. (1978a). The bio-optical state of ocean waters and remote sensing. Limnol. Oceanogr 23: $247-259$

Smith, R. C., Baker, K. S. (1978b). Optical classifucation of natural waters. Limnol. Oceanogr 23: 260-267

Accepted for printing on May 15, 1981 